\title{
VALIDATION OF STANDARDIZED CREATININE AND CYSTATIN C GFR ESTIMATING EQUATIONS IN A LARGE MULTICENTRE EUROPEAN COHORT OF CHILDREN
}

\author{
Jonas Björk ${ }^{1,2} \bullet$ Ulf Nyman ${ }^{3}$ Ulla Berg ${ }^{4}$ Pierre Delanaye ${ }^{5}$ - Laurence Dubourg ${ }^{6} \bullet$ Karolien Goffin $^{7} \bullet$ AndersGrubb $^{8} \bullet$ \\ Magnus Hansson ${ }^{9} \bullet$ Karin Littmann ${ }^{9} \bullet$ Kajsa Åsling-Monemi ${ }^{4} \bullet$ Arend Bökenkamp $^{10} \bullet$ Hans Pottel $^{11}$ \\ Division of Occupational and Environmental Medicine, Lund University, Lund, Sweden \\ Clinical Studies Sweden, Forum South, Skåne University Hospital, Lund, Sweden \\ Department of Translational Medicine, Division of Medical Radiology, Lund University, Malmö, Sweden \\ Department of Clinical Science, Intervention and Technology, Division of Paediatrics, Karolinska Institutet, Karolinska University Hospital \\ Huddinge, Stockholm, Sweden \\ Nephrology-Dialysis-Transplantation, University of Liège, CHU Sart Tilman, Liège, Belgium \\ 6 Néphrologie, Dialyse, Hypertension et Exploration Fonctionnelle Rénale, Groupement Hospitalier Edouard Herriot, Hospices Civils de Lyon, \\ Université Claude Bernard Lyon 1, and Laboratory ofTissue Biology and Therapeutic Engineering, UMR 5305 CNRS, Université Claude Bernard Lyon \\ 1, Lyon, France \\ Department of Nuclear Medicine \& Molecular Imaging, University Hospital Leuven, Leuven, Belgium \\ Department of Clinical Chemistry, Skåne University Hospital, Lund, Lund University, Lund, Sweden \\ Department of Laboratory Medicine, Division of Clinical Chemistry, Karolinska Institutet, Karolinska University Hospital Huddinge, Stockholm, \\ Sweden \\ 10 Emma Children's Hospital, Amsterdam UMC, Vrije Universiteit Amsterdam, Amsterdam, The Netherlands \\ 11 Department of Public Health and Primary Care, KU Leuven Campus Kulak Kortrijk, Kortrijk, Belgium
}

Jonas Björk and Ulf Nyman share first authorship

Arend Bökenkamp and Hans Pottel share senior/last authorship

KEYWORDS Children; Chronic kidney disease; Glomerular filtration rate; Kidney function tests; Renal failure

\begin{abstract}
Background Most validations of paediatric glomernlar filtration rate (GFR) estimating equations using standardized ceatinine (CR) and cystatin C (CYS) assays have comprised relatively small cohorts, which makes accuracy across subgroups of GFR, age, body mass index (BMI) and gender uncertain. To overcome this, a large cohort of children referred for GFR determination has been established from several European medical centres.
\end{abstract}

Methods Three thousand four hundred eight measurements of GFR (mGFR) using plasma clearance of exogenous substances were performed in 2218 children aged 2-17 years. Validated equations included Schwartz-

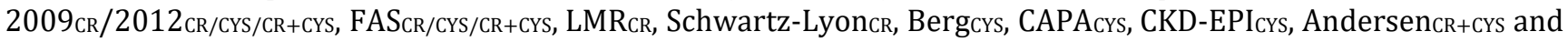
arithmetic means of the best single-marker equations in explorative analysis. Five metrics were used to compare the performance of the GFR equations: bias, precision and three accuracy measures including the percentage of GFR estimates (eGFR) within $\pm 10 \%\left(\mathrm{P}_{10}\right)$ and $\pm 30 \%\left(\mathrm{P}_{30}\right)$ of mGFR.

Results Three of the cystatin C equations, BergCYs, CAPACYs and CKD-EPICYs, exhibited low bias and generally satisfactory accuracy across all levels of mGFR; CKD-EPI ${ }_{\text {cYs }}$ had more stable performance across gender than the two other equations. Among creatinine equations, Schwartz-Lyon ${ }_{C R}$ had the best performance but was inaccurate at $\mathrm{mGFR}<30 \mathrm{~mL} / \mathrm{min} / 1.73 \mathrm{~m}^{2}$ and in underweight patients. Arithmetic means of the best creatinine and cystatin C equations above improved bias compared to the existing composite creatinine+cystatin $\mathrm{C}$ equations.

Conclusions The present study strongly suggests that cystatin $C$ should be the primary biomarker of choice when estimating GFR in children with decreased GFR. Arithmetic means of well-performing single-marker equations improve accuracy further at most mGFR levels and have practical advantages compared to composite equations.

Electronic supplementary material The online version of this article (https://doi.org/10.1007/s00467-018-4185-y) contains supplementary material, which is available to authorized users. 


\section{Introduction}

Accurate assessment of glomerular filtration rate (GFR) in children is essential for correct classification and management of chronic kidney disease (CKD) and for adjusting drug dosage to avoid toxic effects from certain cytostatic drugs, antibiotics and radiographic contrast media. Measuring GFR (mGFR) in terms of clearance of exogenous substances is relatively costly, inconvenient in daily clinical practice and even unavailable in many hospitals, making equations based on plasma/serum concentrations of creatinine or cystatin C to estimate GFR (eGFR) a necessary alternative to evaluate renal function in many situations.

Most validation studies regarding paediatric GFR equations based on standardized creatinine and cystatin C assays have been small, typically with fewer than 400 GFR measurements and with small numbers of patients with decreased GFR [1-13]. Therefore, the accuracy of even commonly used GFR equations in clinical practice is largely unknown across subgroups of GFR, age, body mass index (BMI) and sex.

The aim of the present study was to validate commonly used GFR equations calibrated to International Federation of Clinical Chemistry and Laboratory Medicine (IFCC)- standardized creatinine and cystatin C assays in a large cohort of children pooled from several medical centres across Europe.

\section{Material and methods DATA SOURCES AND PARTICIPANTS}

A new European work group named "European Kidney Function Consortium" (EKFC) has recently been set up at two meetings (Malmö on September 25, 2017 and Copenhagen on May 26, 2018). EKFC took the initiative to collect retrospective data on subjects referred for GFR measurement including sCr, sCys, age, sex, height and weight. For this study, we selected a subset of all available data from this database, restricted to children 2 to 17 full years of age. Five different cohorts (see descriptions in Supplementary Material including Table S1) used in ongoing or published cross-sectional studies between 2004 and 2016 were included from the Netherlands (Amsterdam [7, 1417]), Belgium (Leuven [13]), France (Lyon [12,13]) and Sweden (Lund [7] and Stockholm). Common reasons for determination of mGFR were congenital malformations, hereditary disorders, glomerulopathies, tubular diseases, vascular disorders, malignancies, urinary tract infections, liver diseases, transplantation follow-up and to dose drugs cleared by the kidneys. A study database, fully anonymous and without personal information, was pooled and centralized for the present study at Lund University, Sweden, comprising 3408 measurements of GFR in 2218 children with complete data on sCr, sCys, age, gender, height and weight. All procedures involving subjects and data agreed with the ethical principles for medical research involving human subjects established in the World Medical Association Declaration of Helsinki of 1975, as revised in 2000. The study was reviewed and approved by the Regional Ethical Board in Lund, Sweden.

\section{LABORATORY ASSAYS}

All centres used creatinine assays traceable to isotope dilution mass spectrometry (IDMS). The cystatin C assays were calibrated against the international cystatin C reference material, ERM-DA471/IFCC, except for Lyon before April 2011 where the values were multiplied by 1.11 [13] and for Amsterdam before December 2012 where the values were multiplied by 1.174 [18] for conversion. For the data originating from the Caucasian, Asian, Paediatric and Adult (CAPA) cohort (Lund and part of Amsterdam cohort), extra care was undertaken to assure that the cystatin C assay used was commutable with regard to the reference material [7]. All assays for cystatin C and creatinine for the CAPA cohort were run on the same instrument (Architect ci8200) at one laboratory (Uppsala University Hospital, Sweden). An external quality assessment system (Equalis AB, Sweden) was used to monitor these analyses as well as those from Stockholm.

Details of clearance methods and creatinine and cystatin C assays used in Amsterdam, Leuven, Lund and Lyon have been published earlier (see references in Supplementary Material and Table S1), while unpublished techniques used in Stockholm are described in more detail in Supplementary Material. External quality control was provided by Equalis AB (Uppsala, Sweden, www.equalis.se/en) regarding the iohexol measurements in Lund and Stockholm.

\section{GFR EQUATIONS}

The following GFR equations were analyzed (for equation expressions, see Supplementary Material): 
1. Creatinine-based, general-purpose équations: The Full Age Spectrum based on age (FAS-Age $\mathrm{CR}$ ) and height (FAS$\mathrm{HtCR}_{\mathrm{C}}[12,13,19]$ and the Lund-Malmo revised equation (LMRCR) [20], which was developed for adults but has also been validated in children [21]

2. Creatinine-based, paediatric equations: Schwartz- 2009 CR [1], Schwartz-2012 CR [3] and Schwartz-Lyon ${ }_{\mathrm{CR}}$ [4]

3. Cystatin C-based, general-purpose equations: CAPAcYs [7], FAS ${ }_{\text {CYs }}$ [13] and the Chronic Kidney Disease Epidemiology collaboration equation (CKD-EPICYS) [22], which was developed for adults but has also been validated in children [7]

4. Cystatin C based, paediatric equations: Bergcrs [9] and Schwartz-2012cys [3]. For the latter, the cystatin C values were divided by 1.174 to make the equation suitable for cystatin $C$ values compatible with the international calibrator [18]

5. Composite creatinine and cystatin C-based, general- purpose equations: FAS-Age $C \mathrm{R}+\mathrm{CYs}$ and FAS-HtCR+CYS [13]

6. Composite creatinine and cystatin C-based, paediatric equations: Schwartz-2012 ${ }_{\mathrm{CR}+\mathrm{CYS}}[3]$ and Andersen ${ }_{\mathrm{CR}+\mathrm{CYS}}$ [5], the latter with absolute values normalized to $1.73-\mathrm{m}$ body surface area

\section{STATISTICAL EVALUATION}

All statistical evaluations were conducted using IBM SPSS Statistics (version 25; IBM Corp.), STATA (version 14.2; StataCorp), PROC QUANTREG in SAS 9.4, (SAS Institute Inc., Cary, NC, US) and Microsoft Excel (Microsoft Corporation, Redmond, WA, USA). Five performance metrics were used:

Bias: Median individual differences eGFR - $\mathrm{mGFR}\left(\mathrm{mL} / \mathrm{min} / 1.73 \mathrm{~m}^{2}\right)$

Precision: Interquartile range (IQR) of the differences eGFR - mGFR

Accuracy: Median absolute percentage error (100 |eGFR - mGFR| / mGFR) and the percentage of estimates within \pm 10 and $\pm 30 \%$ of mGFR (labelled $\mathrm{P}_{10}$ and $\mathrm{P}_{30}$ ). $\mathrm{P}_{30}$ accuracy above $75 \%$ is considered "sufficient for good clinical decision-making" but the benchmark is to reach $\mathrm{P}_{30}>90 \%$ [23]

Main results are presented stratified for mGFR below and above $75 \mathrm{~mL} / \mathrm{min} / 1.73 \mathrm{~m}^{2}$, as abnormal GFR in children has been regarded to start below this threshold [24], and by gender. Quantile regression with linear and quadratic fractional polynomials was used to model the relation between age or mGFR and the 50th percentile of eGFR-mGFR (i.e., median bias). Non-parametric and asymptotic 95\% confidence intervals (CI) were calculated for the main results as measures of the statistical uncertainty in medians and proportions ( $\mathrm{P}_{10}$ and $\left.\mathrm{P}_{30}\right)$. We used McNemar's exact test for pairwise comparisons of $\mathrm{P}_{30}$ across different equations for the main results.

In explorative analysis, we evaluated the performance of the arithmetic means of the most accurate creatinine and cystatin C equations compared to composite equations using a more detailed stratification of mGFR $(<30,30-44$, $45-59,60-74,75-89,90-119$ and $\geq 120 \mathrm{~mL} / \mathrm{min} / 1.73 \mathrm{~m}^{2}$ ).

As supplementary results, we restricted the analysis to one randomly chosen measurement per patient in order to obtain statistically independent observations. We also stratified results by age (2-7, 8-12 and 13-17 full years) and by age- and gender-specific BMI percentiles $(<5 \%$ underweight, 5 to $<85 \%$ healthy weight, 85 to $<95 \%$ overweight and $\geq 95 \%$ obese) [25] representative for Dutch children [26]. LMS values ( $L$ curve, skewness; $M$ curve, median; and $S$ curve, coefficient of variation) from reference [26] were converted into BMI percentiles via the $Z$ score which is calculated from $Z=(y / M)^{\mathrm{L}}-1 /(S \times L)$ when $L \neq 0$. The corresponding percentile was obtained from the standard normal distribution, e.g., $z=-1.96$ corresponds to the 2.5 th percentile, $z=0$ to the 50th percentile and $z=+1.96$ to the 97.5 th percentile. We also present results stratified by organ transplantation and individual cohorts. 


\section{Results}

Patient characteristics for the entire cohort ( $n=3408$ measurements) are presented in Table 1 and split by participating centres in Supplementary Material (Table S2). The proportion of organ transplant recipients was substantially higher in patients with $\mathrm{mGFR}$ below $75 \mathrm{~mL} / \mathrm{min} / 1.73 \mathrm{~m}$ (26 versus $4.2 \%)$. Patients with mGFR $<75$ $\mathrm{mL} / \mathrm{min} / 1.73 \mathrm{~m}^{2}$ tended to be older than those with $\mathrm{mGFR} \geq 75 \mathrm{~mL} / \mathrm{min} / 1.73 \mathrm{~m}^{2}$ (median age 13.0 versus 11.9 years), while there were no important differences in gender distribution, weight or height. There was no marked difference in mGFR distribution between boys and girls at any age. Boys and girls also had similar sCr and sCys values overall until puberty. In boys aged 13 to 17 years, however, both $\mathrm{sCr}$ and sCys concentrations were about $15 \%$ higher in boys than in girls of the same age.

Table 1 Patient characteristics of children 2 to $<18$ years of age with descriptive measures given as median values (2.5 and 97.5 percentiles) if not stated otherwise. The numbers (n) and percentages (\%) refer to GFR measurements/unique children

\begin{tabular}{|c|c|c|c|c|c|}
\hline Variables & $\begin{array}{l}\text { All } \\
(n=3408 / 2218)\end{array}$ & $\begin{array}{l}\mathrm{mGFR} \\
<75 \mathrm{~mL} / \mathrm{min} / 1.73 \mathrm{~m}^{2} \\
(n=1068 / 558)\end{array}$ & $\begin{array}{l}\mathrm{mGFR} \\
2 \geq 75 \mathrm{~mL} / \mathrm{min} / 1.73 \\
\mathrm{~m}^{2}(n=2340 / 1806)\end{array}$ & $\begin{array}{l}\text { Girls } \\
3(n=1411 / 924)\end{array}$ & $\begin{array}{l}\text { Boys } \\
(n \\
1997 / 1294)\end{array}$ \\
\hline Girls, number (\%) & $\begin{array}{l}1411 / 924 \\
(41 / 42)\end{array}$ & $425 / 232(40 / 42)$ & $986 / 751(42 / 42)$ & NA & NA \\
\hline Transplants, number (\%) & $\begin{array}{l}378 / 140 \\
(11 / 6.3)\end{array}$ & $279 / 99(26 / 18)$ & $99 / 63(4.2 / 3.5)$ & $127 / 49(9.0 / 5.3)$ & $\begin{array}{l}251 / 91 \\
(13 / 7.0)\end{array}$ \\
\hline Age (years) & $12.3(2.6-17.8)$ & $13.0(3.1-17.7)$ & $11.9(2.5-17.8)$ & $12.0(2.6-17.8)$ & $12.5(2.6-17.7)$ \\
\hline Weight (kg) & $41(13-86)$ & $42(14-86)$ & $40(13-86)$ & $40(13-80)$ & $42(14-88)$ \\
\hline Height $(\mathrm{cm})$ & $148(90-184)$ & $149(91-183)$ & $148(90-185)$ & $147(90-176)$ & $150(90-186)$ \\
\hline Body surface area $\left(\mathrm{m}^{2}\right)$ & $1.31(0.57-2.0)$ & $1.33(0.57-2.02)$ & $1.29(0.56-2.06)$ & $1.29(0.56-1.91)$ & $\begin{array}{l}1.33 \quad \text { (0.57- } \\
2.10) \quad\end{array}$ \\
\hline Body mass index $\left(\mathrm{kg} / \mathrm{m}^{2}\right)$ & $18(14-29)$ & $18(14-31)$ & $18(14-29)$ & $18(13-29)$ & $18(14-30)$ \\
\hline Plasma creatinine $\mu \mathrm{mol} / \mathrm{L}$ ) & $57(21-189)$ & $90(39-328)$ & $48(19-91)$ & $54(21-179)$ & $60(21-201)$ \\
\hline Plasma cystatin C (mg/L) & $1.00(0.62-3.00)$ & $1.55(0.94-4.00)$ & $0.90(0.60-1.39)$ & $0.95(0.60-2.89)$ & $\begin{array}{l}1.05 \\
3.16)\end{array}$ \\
\hline $\begin{array}{l}\text { Measured GFR }(\mathrm{mL} / \mathrm{min} / 1.73 \\
\left.\mathrm{m}^{2}\right) \\
\text { Measured GFR, number }(\%)\end{array}$ & $390(23-165)$ & $56(15-74)$ & $103(77-172)$ & $90(24-165)$ & $91(23-164)$ \\
\hline$\geq 120 \mathrm{~mL} / \mathrm{min} / 1.73 \mathrm{~m}^{2}$ & 607 (18) & NA & $607(26)$ & 244 (17) & 363 (18) \\
\hline $90-119 \mathrm{~mL} / \mathrm{min} / 1.73 \mathrm{~m}^{2}$ & $1149(34)$ & NA & $1149(49)$ & $485(34)$ & $664(33)$ \\
\hline $75-89 \mathrm{~mL} / \mathrm{min} / 1.73 \mathrm{~m}^{2}$ & $584(17)$ & NA & $584(25)$ & 257 (18) & $327(16)$ \\
\hline $60-74 \mathrm{~mL} / \mathrm{min} / 1.73 \mathrm{~m}^{2}$ & $449(13)$ & $449(42)$ & NA & $176(12)$ & $273(14)$ \\
\hline $45-59 \mathrm{~mL} / \mathrm{min} / 1.73 \mathrm{~m}^{2}$ & $285(8.4)$ & $285(27)$ & NA & $121(8.6)$ & $164(8.2)$ \\
\hline $30-44 \mathrm{~mL} / \mathrm{min} / 1.73 \mathrm{~m}^{2}$ & $185(5.4)$ & 185 (17) & NA & $75(5.3)$ & $110(5.5)$ \\
\hline$<30 \mathrm{~mL} / \mathrm{min} / 1.73 \mathrm{~m}^{2}$ & $149(4.4)$ & $149(14)$ & NA & $53(3.8)$ & $96(4.8)$ \\
\hline
\end{tabular}

$m G F R$ measured glomerular filtration rate, $N A$ not applicable

\section{MAIN RESULTS}

\section{CREATININE EQUATIONS}

The paediatric Schwartz-Lyon ${ }_{C R}$ equation exhibited the best or second-best results among the creatinine equations in terms of bias, precision and all three accuracy measures both below and above an mGFR of $75 \mathrm{~mL} / \mathrm{min} / 1.73 \mathrm{~m}^{2}$ (Table 2). The $\mathrm{P}_{30}$ accuracy at $\mathrm{mGFR}<75 \mathrm{~mL} / \mathrm{min} / 1.73 \mathrm{~m}^{2}$ was significantly higher than for all other creatinine equations $(p<0.001)$ except for Schwartz-2012 ${ }_{\text {CR }}(p=0.35)$. Schwartz-Lyon ${ }_{C R}$ also exhibited the most stable performance across the whole spectrum of mGFR, especially at the lowest and highest mGFR intervals (Supplementary Material and Table S3). Underestimations exceeding $20 \mathrm{~mL} / \mathrm{min} / 1.73 \mathrm{~m}$ were noted for Schwartz$2012_{\mathrm{CR}}$ at $\mathrm{mGFR}>120 \mathrm{~mL} / \mathrm{min} / 1.73 \mathrm{~m}^{2}$ and for $\mathrm{LMR}_{\mathrm{CR}}$ at $\mathrm{mGFR}>130 \mathrm{~mL} / \mathrm{min} / 1.73 \mathrm{~m}^{2}$ (Fig. 1a). All creatinine 
equations, however, had poor performance at $\mathrm{mGFR}<30 \mathrm{~mL} / \mathrm{min} / 1.73 \mathrm{~m}^{2}$ with $\mathrm{P}_{30}$ values $\leq 60 \%$ (Supplementary Material and Table S3).

\section{CYSTATIN C EQUATIONS}

Both the general-purpose (CAPACYS, CKD-EPICYs and FAS ${ }_{C Y S}$ ) and the paediatric (Berg ${ }_{\text {CYS }}$ and Schwartz-2012 ${ }_{\text {CYs }}$ ) cystatin C equations had $\mathrm{P}_{30}$ accuracy close to $80 \%$ at $\mathrm{mGFR}<75 \mathrm{~mL} / \mathrm{min} / 1.73 \mathrm{~m}^{2}$ and between 84 and $89 \% \geq 75$ $\mathrm{mL} / \mathrm{min} / 1.73 \mathrm{~m}^{2}$ (Table 2). However, Schwartz-2012cys markedly underestimated mGFR $\geq 75 \mathrm{~mL} / \mathrm{min} / 1.73 \mathrm{~m}^{2}$, resulting in higher absolute percentage error and lower $\mathrm{P}_{10}$ compared to the other cystatin $\mathrm{C}$ equations. Underestimation exceeding $20 \mathrm{~mL} / \mathrm{min} / 1.73 \mathrm{~m}$ was noted for Schwartz- 2012 cys at mGFR $>120 \mathrm{~mL} / \mathrm{min} / 1.73 \mathrm{~m}^{2}$ but also for $\mathrm{FAS}_{\text {cys }}$ at mGFR $>135 \mathrm{~mL} / \mathrm{min} / 1.73 \mathrm{~m}^{2}$ (Fig. 1b). Bergcys, CAPAcys and CKD-EPI cys exhibited low bias and

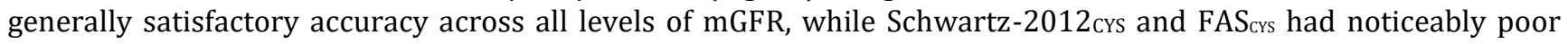
performance at mGFR $<30 \mathrm{~mL} / \mathrm{min} / 1.73 \mathrm{~m}^{2}$ with $\mathrm{P}_{30}<40 \%$ (Supplementary Material and Table S3).

\section{COMPOSITE CREATININE AND CYSTATIN C EQUATIONS}

The composite creatinine and cystatin $\mathrm{C}$ equations were consistently more precise than the single-marker equations at all mGFR levels. However, at mGFR $<75 \mathrm{~mL} / \mathrm{min} / 1.73 \mathrm{~m}^{2}$, all composite equations had a positive bias (Fig. 1c). Therefore, accuracy was not superior to the most accurate single-marker equations at mGFR $<75 \mathrm{~mL} / \mathrm{min} / 1.73 \mathrm{~m}^{2}$ (Table 2). All composite equations had poor $\mathrm{P}_{30}$ accuracy at $\mathrm{mGFR}<30 \mathrm{~mL} / \mathrm{min} / 1.73 \mathrm{~m}$ (Supplementary Material and Table S3). $\mathrm{P}_{30}$ accuracy of all composite equations exceeded $90 \%$ at $\mathrm{mGFR} \geq 75 \mathrm{~mL} / \mathrm{min} / 1.73 \mathrm{~m}^{2}$, which was higher than for any of the single-marker equations (Table 2). Underestimations exceeding $20 \mathrm{~mL} / \mathrm{min} / 1.73 \mathrm{~m}$ were noted for Schwartz-2012 $2_{\mathrm{CR}+\mathrm{CYS}}$ at $\mathrm{mGFR}>140 \mathrm{~mL} / \mathrm{min} / 1.73 \mathrm{~m}^{2}$ (Fig. 1c).

a

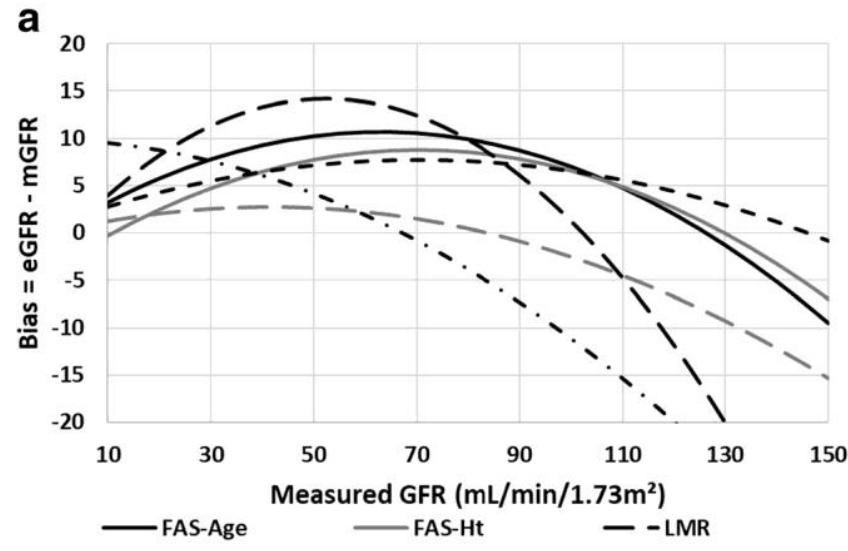

b

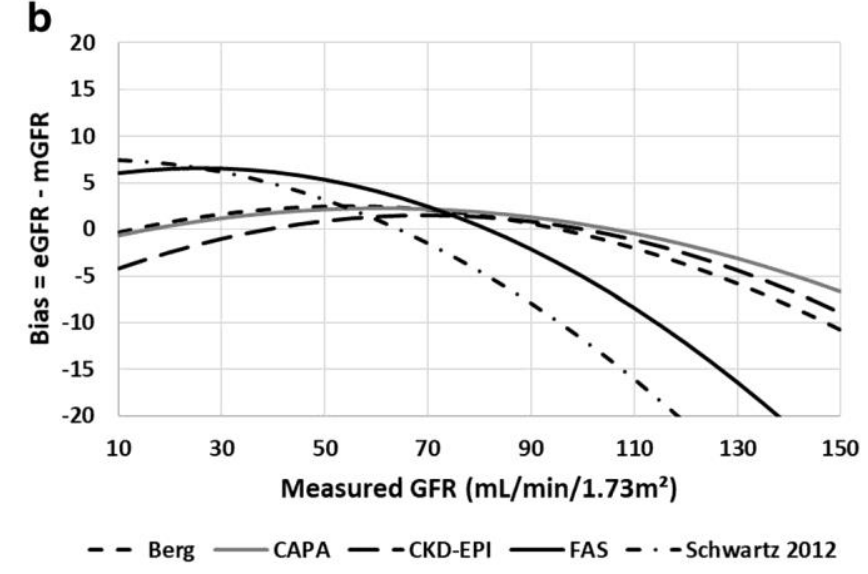

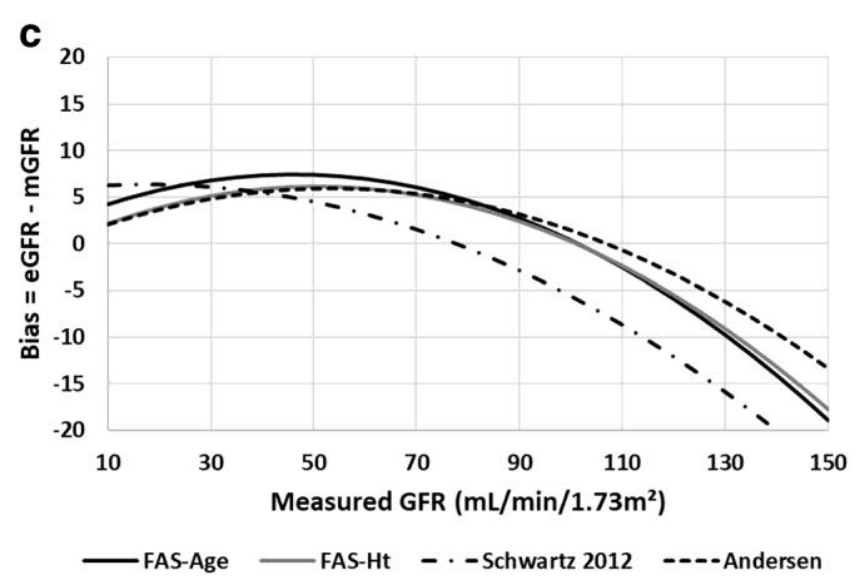

Fig. 1 Quantile regression for the relation between mGFR and median bias (50th percentile of eGFR-mGFR) in $\mathrm{mL} / \mathrm{min} / 1.73 \mathrm{~m}^{2}$ of $\boldsymbol{a}$ creatinine equations, $\boldsymbol{b}$ cystatin $C$ equations and $\boldsymbol{c}$ composite creatinine and cystatin $C$ equations. eGFR estimated glomerular filtration rate, mGFR measured glomerular filtration rate, CAPA Caucasian, Asian, Paediatric and Adult equation, CKD-EPI Chronic Kidney Disease Epidemiology collaboration equation, FAS 


\section{Full Age Spectrum equation, Ht height, LMR Lund-Malmo revised equation}

Table 2 Bias, precision and accuracy (95\% confidence intervals) of GFR estimating equations based on creatinine, cystatin $C$ and their combinations in children 2 to $<18$ years $(\mathrm{n}=3408$ measurements) and stratified for measured GFR $<75(n=1068)$ and $\geq 75 \mathrm{~mL} / \mathrm{min} / 1.73 \mathrm{~m}^{2}(\mathrm{n}=2340)$

\begin{tabular}{|c|c|c|c|c|c|}
\hline Equations & $\begin{array}{l}\text { Bias } \\
\left(\mathrm{mL} / \mathrm{min} / 1.73 \mathrm{~m}^{2}\right)\end{array}$ & $\begin{array}{l}\text { Precision } \\
\left(\mathrm{mL} / \mathrm{min} / 1.73 \mathrm{~m}^{2}\right)\end{array}$ & $\begin{array}{l}\text { Absolute percentage } \\
\text { error }\end{array}$ & $\mathrm{P}_{10}(\%)$ & $\mathrm{P}_{30}(\%)$ \\
\hline \multicolumn{6}{|c|}{ mGFR $<75$ (median 56) $\mathrm{mL} / \mathrm{min} / 1.73 \mathrm{~m}^{2}$ Creatinine } \\
\hline FAS-Age & $9.5(8.5$ to 10.2$)$ & 15.9 & 20.3 (18.8 to 22.0$)$ & $27.0(24.3$ to 29.6$)$ & $66.8(63.9$ to 69.6$)$ \\
\hline FAS-Height & $6.6(5$. To 7.2$)$ & 15.8 & $16.4(15.5$ to 18.0$)$ & $33.1(30.2$ to 35.9$)$ & $72.3(69.6$ to 75.0$)$ \\
\hline LMR & $13.1(11.8$ to 14.0$)$ & 19.1 & 25.7 (23.9 to 27.5$)$ & $22.8(20.2$ to 25.3$)$ & 56.7 (53.8 to 59.7$)$ \\
\hline Schwartz-2009 & $6.9(5.9$ to 7.6$)$ & 15.1 & 16.7 (15.3 to17.8) & $31.0(28.2$ to 33.8$)$ & 73.0 (70.4 to 75.7$)$ \\
\hline Schwartz-2012 & $4.1(3.3$ to 4.7$)$ & 11.5 & $13.1(12.4$ to 14.0$)$ & $41.5(38.5$ to 44.4$)$ & 81.1 (78.7 to 83.4$)$ \\
\hline Schwartz-Lyon & $2.3(1.5$ to 3.1$)$ & 13.0 & 12.7 (12.0 to 13.7$)$ & $39.4(36.5$ to 42.4$)$ & 82.0 (79.7 to 83.4$)$ \\
\hline \multicolumn{6}{|l|}{ Cystatin $C$} \\
\hline Berg & $1.1(0.2$ to 1.7$)$ & 13.1 & 13.7 (12.7 to 14.8$)$ & $37.2(34.3$ to 40.1$)$ & 81.1 (78.7 to 84.4$)$ \\
\hline CAPA & $1.1(0.4$ to 1.9$)$ & 15.2 & 15.414 .3 to 16.6$)$ & 33.7 (30.9 to 36.5) & 79.0 (76.6 to 81.5$)$ \\
\hline CKD-EPI & $-1.1(-1.7$ to -0.5$)$ & 13.4 & 14.9 (13.8 to 15.9$)$ & 36.6 (33.7 to 39.5) & 80.3 (78.0 to 82.7$)$ \\
\hline FAS & 4.5 (3.6 to 5.0$)$ & 12.2 & $14.5(13.4$ to 15.6$)$ & $36.6(33.7$ to 39.5$)$ & $77.6(75.1$ to 80.1$)$ \\
\hline Schwartz-2012 & $2.4(1.7$ to 3.1$)$ & 12.4 & 13.3 (12.1 to 14.7$)$ & 39.7 (36.8 to 42.6) & $81.6(79.2$ to 83.9$)$ \\
\hline \multicolumn{6}{|c|}{ Creatinine +cystatin $C$} \\
\hline FAS-AGE & 6.1 (5.4 to 6.9$)$ & 10.9 & $15.0(13.6$ to 16.3$)$ & 37.8 (34.9 to 40.7) & 77.4 (74.9 to 79.9$)$ \\
\hline FAS-Height & $4.9(4.4$ to 5.4$)$ & 11.4 & 13.0 (12.0 to 14.0$)$ & 39.8 (36.9 to 42.7) & 81.5 (79.1 to 83.8$)$ \\
\hline Schwartz-2012 & 4.4 (3.8 to 4.9$)$ & 10.6 & 12.9 (12.0 to 13.7$)$ & 40.9 (38.0 to 43.9) & 81.9 (79.6 to 84.2$)$ \\
\hline Andersen & $4.0(3.3$ to 4.6$)$ & 11.6 & 12.111 .1 to 13.1$)$ & 43.0 (40.0 to 45.9$)$ & 82.4 (80.1 to 84.7$)$ \\
\hline \multicolumn{6}{|c|}{$m G F R \geq 75$ (median 103) $\mathrm{mL} / \mathrm{min} / 1.73 \mathrm{~m}^{2}$} \\
\hline \multicolumn{6}{|c|}{ Creatinine } \\
\hline FAS-Age & 5.8 (4.6 to 6.7$)$ & 27.9 & $13.5(12.9$ to 14.1$)$ & $38.6(36.7$ to 40.6$)$ & $82.4(80.8$ to 83.9$)$ \\
\hline FAS-Height & $5.4(4.3$ to 6.4$)$ & 29.1 & $13.6(12.7$ to 14.4$)$ & $38.2(36.2$ to 40.2$)$ & $82.0(80.4$ to 83.5$)$ \\
\hline LMR & $-4.1(-5.0$ to -3.1$)$ & 26.2 & $12.5(11.8$ to 13.3$)$ & $41.1(39.1$ to 43.1$)$ & $88.2(86.9$ to 89.5$)$ \\
\hline Schwartz-2009 & $5.2(4.1$ to 6.6$)$ & 29.8 & $14.7(14.1$ to 15.5$)$ & $35.2(33.2$ to 37.1$)$ & $81.5(79.9$ to 83.1$)$ \\
\hline Schwartz-2012 & $-13.2(-14.0$ to -12.3$)$ & 22.7 & $15.2(14.6$ to 16.8$)$ & $32.5(30.6$ to 34.4$)$ & $85.9(84.4$ to 87.3$)$ \\
\hline Schwartz-Lyon & $-3.6(-4.7$ to -2.3$)$ & 26.0 & $13.5(12.7$ to 14.1$)$ & 38.8 (36.8 to 40.8$)$ & $87.1(85.7$ to 88.4$)$ \\
\hline \multicolumn{6}{|l|}{ Cystatin C } \\
\hline Berg & $-1.1(-2.2$ to -0.2$)$ & 28.3 & $13.8(13.0$ to 14.3$)$ & 38.5 (36.5 to 40.4$)$ & 83.8 (82.3 to 85.3$)$ \\
\hline CAPA & $-0.4(-1.5$ to -0.6$)$ & 30.1 & 14.4 (13.6 to 15.0$)$ & 36.7 (34.7 to 38.6 ) & $84.6(83.2$ to 86.1$)$ \\
\hline CKD-EPI & $-1.6(-2.6$ to -0.7$)$ & 27.2 & 13.1 (12.5 to 13.7$)$ & 39.6 (37.6 to 41.6$)$ & $87.5(86.1$ to 88.8$)$ \\
\hline FAS & $-6.2(-7.0$ to -5.4$)$ & 24.3 & $12.9(12.2$ to 13.7$)$ & 40.1 (38.1 to 42.1) & $88.9(87.7$ to 90.2$)$ \\
\hline Schwartz 2012 & $-13.3(-14.1$ to -12.3$)$ & 22.7 & $15.0(14.2$ to 15.6$)$ & 31.9 (30.0 to 33.8) & $85.9(84.4$ to 87.3$)$ \\
\hline \multicolumn{6}{|c|}{ Creatinine+cystatin $C$} \\
\hline FAS-AGE & $-0.9(-1.7$ to -0.2$)$ & 21.2 & 10.2 (9.7 to 10.8$)$ & $49.2(47.2$ to 51.2$)$ & $93.4(92.4$ to 94.4$)$ \\
\hline FAS-Height & $-1.2(-2.0$ to -0.5$)$ & 20.8 & 10.1 (9.7 to 10.6$)$ & $49.2(47.2$ to 51.3$)$ & $93.2(92.1$ to 94.2$)$ \\
\hline Schwartz-2012 & $-7.0(-7.9$ to -6.3$)$ & 19.7 & $11.0(10.5$ to 11.6$)$ & 46.1 (44.0 to 48.1) & 93.1 (92.0 to 94.1$)$ \\
\hline Andersen & $-1.3(-2.1$ to -0.5$)$ & 21.7 & $10.8(10.3$ to 11.4$)$ & 46.8 (44.8 to 48.9$)$ & $91.4(90.2$ to 92.5$)$ \\
\hline
\end{tabular}

Median bias (eGFR - mGFR) and precision (interquartile range) expressed in $\mathrm{mL} / \mathrm{min} / 1.73 \mathrm{~m}^{2}$ and accuracy expressed as median absolute percentage error $\left(100^{\circ} \mid\right.$ eGFR $\left.-\mathrm{mGFR} \mid / \mathrm{mGFR}\right)$ and $\mathrm{P}_{10}$ and $\mathrm{P}_{30}$ accuracy (percentage of GFR estimates within \pm 10 and $\pm 30 \%$ of $\mathrm{mGFR}$ ). $\square \mathrm{P}_{30}<75 \%$, $\square \mathrm{P}_{30} 75$ to $<90 \%, \square \mathrm{P}_{30} \geq 90 \%$

CAPA Caucasian, Asian, Paediatric and Adult, CKD-EPI Chronic Kidney Disease Epidemiology collaboration, FAS Full Age Spectrum, LMR Lund- Malmo revised, $e G F R$ estimated glomerular filtration rate, $m G F R$ measured glomerular filtration rate 


\section{STRATIFICATION FOR GENDER}

Most creatinine equations had equal performance in girls and boys both below and above an mGFR of 75 $\mathrm{mL} / \mathrm{min} / 1.73 \mathrm{~m}$ (Table 3). Notably, Schwartz-Lyon ${ }_{\mathrm{CR}}$, a modification of Schwartz-2009 ${ }_{\text {CR }}$ with a lower $k$ factor (32.5 instead of 36.5) in all girls and in boys $<13$ years, performed better than Schwartz-2009 CR both below and above an mGFR of $75 \mathrm{~mL} / \mathrm{min} / 1.73 \mathrm{~m}^{2}$. CKD-EPICYs, the only cystatin C equation with a gender factor, exhibited equal performance among girls and boys both below and above mGFR $75 \mathrm{~mL} / \mathrm{min} / 1.73 \mathrm{~m}^{2}$, while the other cystatin Cbased equations had lower $\mathrm{P}_{30}$ accuracy in girls compared to boys at mGFR $<75 \mathrm{~mL} / \mathrm{min} / 1.73 \mathrm{~m}$ (Table 3). The improvement in performance of the composite equations at $\mathrm{mGFR} \geq 75 \mathrm{~mL} / \mathrm{min} / 1.73 \mathrm{~m}$ was noted in both boys and girls.

\section{ARITHMETIC MEANS OF CREATININE AND CYSTATIN C EQUATIONS}

In the explorative analysis, the performance of the arithmetic means of the most accurate creatinine and cystatin $\mathrm{C}$ equations was evaluated; Schwartz-Lyon ${ }_{C R}$ combined with Berg ${ }_{\text {CYs, }}$ CAPA CYS $_{\text {or }}$ or CKD-EPI ${ }_{\text {Cys }}$ (Supplementary Material, Table S3 and Fig. S1). All three performed similarly, generally with decreased bias irrespective of mGFR level and improved $\mathrm{P}_{30}$ accuracy below $45 \mathrm{~mL} / \mathrm{min} / 1.73 \mathrm{~m}$ compared to the composite equations. The $\mathrm{P}_{30}$ accuracy was equal or higher than for any of the three corresponding cystatin C equations at all mGFR levels $\geq 30 \mathrm{~mL} / \mathrm{min} / 1.73 \mathrm{~m}^{2}$.

\section{SUPPLEMENTARY RESULTS}

Restricting the analysis to one randomly chosen measurement per patient did not change overall results markedly but reduced statistical precision. As an example, $\mathrm{P}_{30}$ for Schwartz- LyoncR was 79.0\% (95\% CI 75.3 to 82.6\%) among 480 unique patients with $\mathrm{mGFR}<75 \mathrm{~mL} / \mathrm{min} / 1.73 \mathrm{~m}^{2}$ compared with $82.0 \%$ (95\% CI 79.7 to $83.4 \%$ ) among all measurements (Table 2). Corresponding figures for 1738 unique patients with mGFR $>75 \mathrm{~mL} / \mathrm{min} / 1.73 \mathrm{~m}^{2}$ were $85.7 \%$ (95\% CI 84.0 to $87.3 \%$ ) compared with $87.1 \%$ (95\% CI 85.7 to $88.4 \%$ ) among all measurements.

\section{STRATIFICATION FOR AGE}

Schwartz-Lyon ${ }_{\mathrm{CR}}$, Berg $\mathrm{CYS}_{\mathrm{S}}$ and CKD-EPI $\mathrm{CYS}_{\mathrm{S}}$ had relatively stable and adequate performance in all age groups both below and above mGFR of $75 \mathrm{~mL} / \mathrm{min} / 1.73 \mathrm{~m}^{2}$ (Fig. 2a-c, Supplementary Material and Table S4). The improvement in performance for the composite equations at an $\mathrm{mGFR} \geq 75 \mathrm{~mL} / \mathrm{min} / 1.73 \mathrm{~m}^{2}$ was seen across all age groups. The arithmetic means of Schwartz-Lyon CR combined with Berg ${ }_{C Y S}$, CAPA $A_{C Y S}$ or CKD-EPI ${ }_{C Y S}$ had a stable performance across all age groups except for the combination with CAPA below the age of 6 years (Supplementary Material and Fig. S2).

\section{STRATIFICATION FOR BMI}

In general, all creatinine equations had a marked positive bias in underweight patients both below and above mGFR of $75 \mathrm{~mL} / \mathrm{min} / 1.73 \mathrm{~m}^{2}$, while bias of the cystatin C equations was lower (Supplementary Material and Table S5A and B). Despite this, none of the cystatin C equations had $\mathrm{P}_{30}$ accuracy above $75 \%$ in underweight patients at mGFR $<75 \mathrm{~mL} / \mathrm{min} / 1.73 \mathrm{~m}^{2}$, while this was the case at $\mathrm{mGFR}>75 \mathrm{~mL} / \mathrm{min} / 1.73 \mathrm{~m}^{2}$ and in obese patients irrespective of mGFR level.

\section{PATIENTS WITH ORGAN TRANSPLANTS}

All equations performed at least as well in transplanted as in the other patients, both at mGFR below and above 75 $\mathrm{mL} / \mathrm{min} / 1.73 \mathrm{~m}^{2}$ (Supplementary Material and Table S6).

\section{RESULTS IN INDIVIDUAL COHORTS}

Bias and $\mathrm{P}_{30}$ accuracy of the various GFR equations in the individual cohorts are presented in Supplementary Material (Table S7A and B). In general, the bias of the cystatin $\mathrm{C}$ equations varied more across the cohorts compared with the creatinine equations. Of note, in the Lund Cohort, all cystatin C equations had a negative bias at mGFR $\geq 75 \mathrm{~mL} / \mathrm{min} / 1.73 \mathrm{~m}^{2}$. The cohort from Leuven had only 16 measurements below $75 \mathrm{~mL} / \mathrm{min} / 1.73 \mathrm{~m}^{2}$ and these results should therefore be interpreted with caution. 
Table 3 Bias and accuracy $\left(P_{30}\right)$ of GFR estimating equations based on creatinine, cystatin $C$ and their combinations in children 2 to $<18$ years old $(n=3408$ measurements) and stratified by gender and measured GFR $<75$ and $(n=$ $1068) \geq 75 \mathrm{~mL} / \mathrm{min} / 1.73 \mathrm{~m}^{2}(\mathrm{n}=2340)$

\begin{tabular}{|c|c|c|c|c|c|c|c|c|c|c|c|c|c|c|c|c|c|}
\hline Equations & n $(\%)$ & \multicolumn{7}{|c|}{ Creatinine } & \multicolumn{5}{|c|}{ Cystatin C } & \multicolumn{4}{|c|}{ Creatinine and cystatin $\mathrm{C}$} \\
\hline $\begin{array}{l}\text { mGFR }<75 \\
\text { Bias }\end{array}$ & $\mathrm{mL} / \mathrm{min} /$ & $1.73 \mathrm{~m}^{2}$ & & & & & & & & & & & & & & & \\
\hline Girls & $425(40)$ & 55 & 10.0 & 7.5 & 9.3 & 8.9 & 5.6 & 2.5 & 4.0 & 4.1 & 0.1 & 7.4 & 5.4 & 8.4 & 6.7 & 6.5 & 5.8 \\
\hline Girls & & & 65 & 73 & 70 & 71 & 78 & 83 & 77 & 74 & 80 & 72 & 79 & 72 & 78 & 78 & 80 \\
\hline Boys & & & 68 & 72 & 48 & 75 & 83 & 81 & 84 & 82 & 81 & 81 & 84 & 81 & 84 & 85 & 84 \\
\hline $\begin{array}{l}\text { mGFR } \geq 75 \\
\text { Bias }\end{array}$ & $\mathrm{mL} / \mathrm{min}$ & $1.73 \mathrm{~m}^{2}$ & & & & & & & & & & & & & & & \\
\hline Girls & $986(42)$ & 102 & 7.1 & 7.0 & -6.4 & 9.3 & 10.6 & -2.5 & 4.7 & 5.7 & -0.3 & -2.0 & -9.1 & 2.2 & 1.6 & -3.5 & 3.1 \\
\hline Boys & & & 83 & 81 & 88 & 82 & 83 & 87 & 86 & 85 & 88 & 89 & 84 & 94 & 94 & 92 & 93 \\
\hline
\end{tabular}

Median bias (eGFR - mGFR) expressed in $\mathrm{mL} / \mathrm{min} / 1.73 \mathrm{~m}$ and $\mathrm{P}_{30}$ accuracy as percentage of GFR estimates within $\pm 30 \%$ of $\mathrm{mGFR}$. $\square \mathrm{P}_{30}<75 \%$, $\square \mathrm{P}_{30} 75$ to $<90 \%, \square \mathrm{P}_{30} \geq 90 \%$

CAPA Caucasian, Asian, Paediatric and Adult, CKD-EPIChronic Kidney Disease Epidemiology collaboration, FAS Full Age Spectrum, LMR LundMalmô revised, $e G F R$ estimated glomerular filtration rate, $m G F R$ measured glomerular filtration rate

a

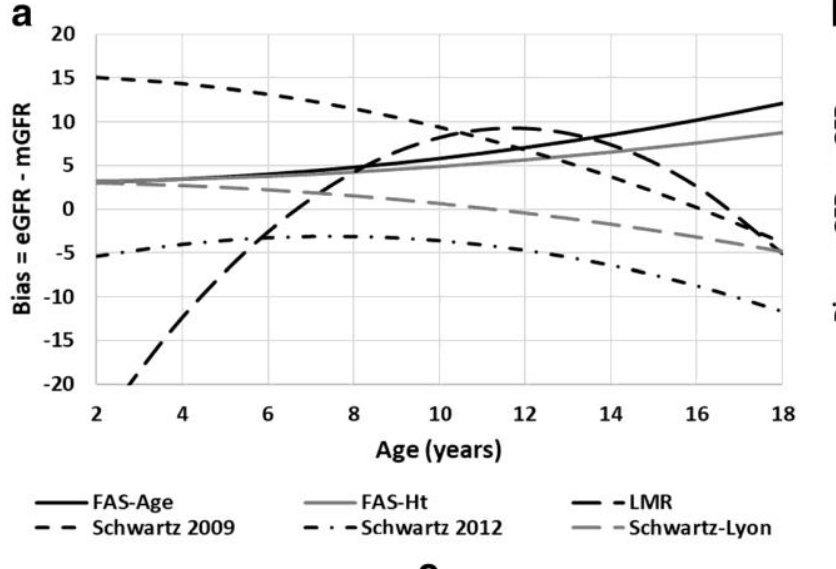

b 20

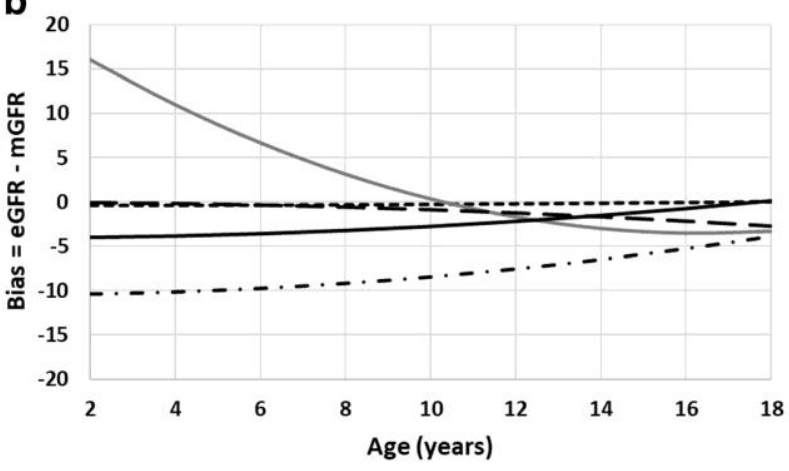

---Berg —CAPA - -CKD-EPI — FAS - - -Schwartz 2012

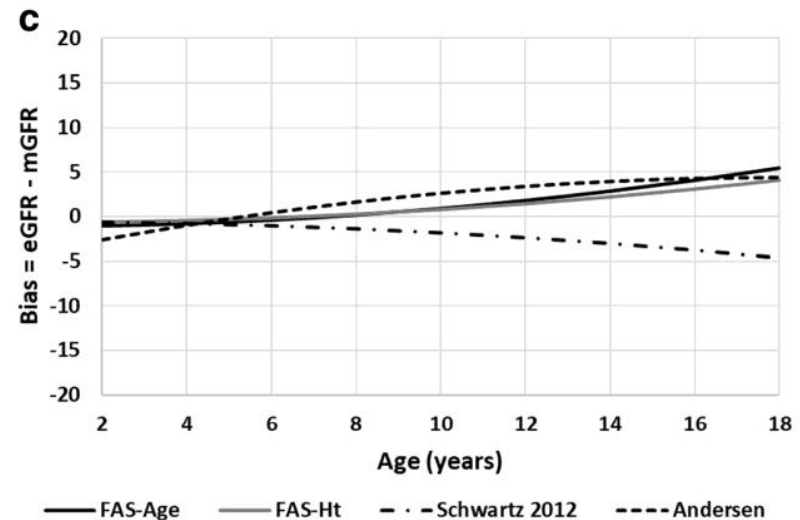

Fig. 2 Quantile regression for the relation between age and median bias (50th percentile of eGFR-mGFR) in $\mathrm{mL} / \mathrm{min} / 1.73 \mathrm{~m}^{2}$ of a creatinine equations, $\boldsymbol{b}$ cystatin $C$ equations and $\boldsymbol{c}$ composite creatinine and cystatin $C$ equations. eGFR estimated glomerular filtration rate, mGFR measured glomerular filtration rate, CAPA Caucasian, Asian, Paediatric and Adult equation, CKD-EPI Chronic Kidney Disease Epidemiology collaboration equation, FAS 
Published in : Pediatric Nephrology (2019).

https://doi.org/10.1007/s00467-018-4185-y

Status : Postprint (author's version)

Full Age Spectrum equation, Ht height, LMR Lund-Malmo revised equation 


\section{Discussion}

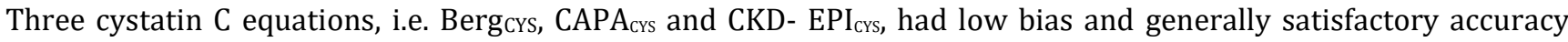
across all levels of mGFR. By contrast, the creatinine equations were generally hampered by substantial overestimation and lack of accuracy in children with decreased renal fonction. Only the paediatric Schwartz-LyoncR equation had satisfactory performance at all mGFR levels $\geq 30 \mathrm{~mL} / \mathrm{min} / 1.73 \mathrm{~m}^{2}$. Arithmetic means ofthese best-performing creatinine and cystatin $C$ equations generally lead to further improvement in accuracy at all mGFR levels $\geq 30$ $\mathrm{mL} / \mathrm{min} / 1.73 \mathrm{~m}^{2}$.

The present, multi-centre study is the largest validation of GFR equations in children conducted to date. The cohort represents children, mainly of Caucasian descent, from several European countries and covers the age span between 2 and 17 full years of age, both girls and boys and with a broad spectrum of diagnoses. Therefore, the findings are applicable in daily clinical practice and extend beyond the populations where the various GFR equations were developed. Importantly, both creatinine and cystatin C were analyzed using IFCC standards at all participating centres.

The varying results for the cystatin $\mathrm{C}$ equations across the different cohorts suggest that residual differences remain in calibration despite the international standard [27-29]. In the Lund cohort, all cystatin $\mathrm{C}$ equations had a marked negative bias at $\mathrm{mGFR} \geq 75 \mathrm{~mL} / \mathrm{min} / 1.73 \mathrm{~m}^{2}$, although a meticulous technique was used to make the cystatin $\mathrm{C}$ assay traceable to the international calibrator in this cohort [7]. This may indicate that the cystatin $C$ assays used when developing BergCYS, CKD-EPICYs, FAS CYs $_{\text {and }}$ Schwartz-2012 ${ }_{\text {cYs }}$ were suboptimized in relation to the international calibrator. Although the Lund cohort was used for the development CAPAcYs, it also had a marked negative bias. This may be explained by the fact that the Lund paediatric cohort formed only a minor part of the entire development cohort, which was dominated by Swedish and Japanese adults. This may have affected the coefficients of CAPA crs $_{\text {and }}$ and resulted in the negative bias in children observed in our study. It should also be noted that roughly $20 \%$ of the included measurements were used previously in the development or internal validation of CAPAcys, Schwartz-Lyoncr and the FAS equations, which may have favored the performance of these equations. Blood urea nitrogen was not available in all cohorts so that the most elaborate CKiD-3 equation [3] could not be tested. The choice of the arithmetic mean equations was driven by the results for the single-marker equations. This may have favored the performance of arithmetic means when compared to the composite creatinine-cystatin $\mathrm{C}$ equations.

The present study adds substantial evidence suggesting that cystatin $\mathrm{C}$ is a more reliable filtration marker than creatinine for GFR estimations in children with decreased GFR. CKD-EPICYs was originally developed for adults [22] but nevertheless exhibited surprisingly stable performance across all levels of GFR in the present cohort of children. Although the CKD-EPI ${ }_{\mathrm{CYs}}$ did not outperform some of the paediatric cystatin $\mathrm{C}$ equations with simpler formula expressions, it has the advantage of covering the whole age spectrum from childhood to adulthood, which may prove attractive for direct eGFR reporting by clinical laboratories. This also applies to CAPA cys $_{\text {and FAS }}$ crs, although

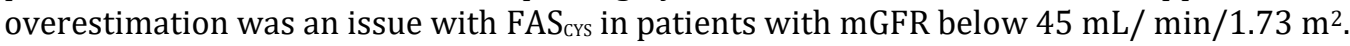

The CKD-EPI ${ }_{\text {crs }}$ equation has a factor of 0.932 for females, which to some extent accounts for the lower cystatin $\mathrm{C}$ values among girls than boys during puberty at the same GFR in the present study. Gender-specific differences in cystatin $C$ concentrations during puberty have also been observed by others $[30,31]$. The other cystatin $C$ equations do not include separate gender factors, which may explain why they generally perform less well in girls with decreased GFR. Based on our findings, inclusion of a-possibly age-dependent-gender factor appears to be a straightforward modification for some of the cystatin C- based equations, which would most likely improve their performance in the future.

The best-performing creatinine equation Schwartz- LyoncR is a paediatric equation with a simplistic formulation based on creatinine and height only. It confirms the concept that the age dependence of creatinine can be accounted for in most cases by inclusion of height in the estimation, at least when mGFR is above $30 \mathrm{~mL} / \mathrm{min} / 1.73 \mathrm{~m}$. Schwartz-Lyoncr equation uses a lower $k$ value for boys under the age of 13 and for all girls and clearly outperforms Schwartz-2009 $\mathrm{CR}$. As the Schwartz-2009 $\mathrm{CR}$ equation-in contrast to the original formulation of the Schwartz equation [32]-does not account for gender- specific differences in body composition, this suggests that genderspecific differences in creatinine production need to be accounted for in order to assure optimal performance.

$\mathrm{LMR}_{\mathrm{CR}}$ was originally developed for adults [20] and has been shown to outperform the CKD-EPI creatinine equation $\left(\mathrm{CKD}-\mathrm{EPI}_{\mathrm{CR}}\right)$ in several adult cohorts, both overall and across important subgroups [33-38]. While CKD- EPI $\mathrm{CR}_{\mathrm{C}}$ unsuitable in children [21], the present study demonstrates that $\mathrm{LMR}_{\mathrm{CR}}$ performs quite well in children with mGFR $75-119 \mathrm{~mL} / \mathrm{min} / 1.73 \mathrm{~m}$ but is unsuitable outside this range. 
The FAS-AGE ${ }_{C R}$ equation was developed with the intention of covering the full age spectrum in children and adults of all ages irrespective of GFR level [13, 12]. This approach eliminates the discontinuous course of eGFR at the transition from adolescence to adulthood due to the change of equation, e.g. from a Schwartz- equation to CKD-EPI $[39,40]$. As $F A S-A G E_{C R}$, like $L_{M R}$, does not require height data, eGFR can be reported automatically by the laboratories. Consistent with a previous study [13], we find satisfactory bias and accuracy for all FAS equations in children with normal GFR but overestimation in children with decreased GFR. Validation studies in adults with CKD have shown substandard accuracy of the FAS equations $[12,38]$, however. The $\mathrm{FAS}_{\mathrm{CR}}$ equation corrects for differences in sCr levels with respect to gender (starting at adolescence), age and height. The formula assumes a simplistic inverse relationship between GFR and $s \mathrm{Cr} / \mathrm{Q}$. While this seems to work well within a certain range of normal $\mathrm{sCr}$ values, the relation is probably more complex when $\mathrm{sCr}$ becomes too high. This is not surprising when looking at most modern GFR equations, which were built using linear regression analysis following logarithmic transformation [41]. In a similar way, the concept of FAS $\mathrm{CYS}_{\mathrm{C}}$ is based on average GFR and cystatin $\mathrm{C}$ for a healthy population. It thus seems that the FAS equations in their present form can only be recommended in patients with normal or mildly impaired renal function and need to be reformulated in patients with low GFR.

Previous studies have shown improved GFR estimation performance when creatinine and cystatin $\mathrm{C}$ are combined in children $[1,3,5,42]$. The present study extends on these results by showing that this improvement is not evident in children with decreased GFR when existing composite equations are applied. However, our explorative results suggest that improvement in performance can be obtained at most levels of mGFR if an arithmetic mean of the bestperforming creatinine and cystatin $\mathrm{C}$ equations is used. This is in line with previous studies showing that the simple arithmetic means of existing single-marker equations tend to perform as well as more complex formulations that include both markers $[21,43,44]$. This approach also alerts the clinician to situations where one of the two GFR markers fails such as creatinine in spina bifida patients or cystatin C during high-dose glucocorticoid treatment [43, $45,46]$.

\section{Conclusion}

The present study strongly suggests that cystatin $C$ should replace creatinine as the primary biomarker of choice when estimating GFR in children with moderately to severely decreased GFR. Arithmetic means of well-performing creatinine and cystatin $C$ equations can be expected to improve accuracy at most mGFR levels and have practical advantages compared to composite equations. However, if high precision is required, e.g. in patients with severely decreased GFR, GFR measurement by exogenous clearance markers is recommended. EKFC and its data resources offer an excellent opportunity for refining GFR equations further, both among children and adults. Development of full-age-spectrum equations and estimation strategies that utilize both creatinine and cystatin $\mathrm{C}$ applicable for both children and adults irrespective of their GFR level would greatly facilitate direct eGFR reporting by the clinical laboratory and solve the problem of abrupt jumps in eGFR during the transition from child- to adulthood due to the changes from a paediatric to an adult GFR equation.

\section{COMPLIANCE WITH ETHICAL STANDARDS}

Conflict of interest The authors declare that they have no conflict of interest.

Ethical approval All procedures performed in studies involving human participants were in accordance with the ethical standards of the institutional and/or national research committee and with the World Medical Association Declaration of Helsinki of 1975, as revised in 2000.

Informed consent For this type of retrospective study, all extracted data were fully anonymous without any personal information, why informed consent was not required according to the regional ethical board approval in, Lund, Sweden, which approved the study.

Publisher's note Springer Nature remains neutral with regard to jurisdictional claims in published maps and institutional affiliations. 


\section{References}

1. Schwartz GJ, Munoz A, Schneider MF, Mak RH, Kaskel F, Warady BA, Furth SL (2009) New equations to estimate GFR in children with CKD. J Am Soc Nephrol 20:629-637

2. Bacchetta J, Cochat P, Rognant N, Ranchin B, Hadj-Aissa A, Dubourg L (2011) Which creatinine and cystatin C equations can be reliably used in children? Clin J Am Soc Nephrol 6:552-560

3. Schwartz GJ, Schneider MF, Maier PS, Moxey-Mims M, Dharnidharka VR, Warady BA, Furth SL, Munoz A (2012) Improved equations estimating GFR in children with chronic kidney disease using an immunonephelometric determination of cystatin C. Kidney Int 82:445-453

4. De Souza VC, Rabilloud M, Cochat P, Selistre L, Hadj-Aissa A, Kassai B, Ranchin B, Berg U, Herthelius M, Dubourg L (2012) Schwartz formula: is one k-coefficient adequate for all children? PLoS One 7:e53439

5. Andersen TB, Jodal L, Boegsted M, Erlandsen EJ, Morsing A, Frokiaer J, Brochner-Mortensen J (2012) GFR prediction from cystatin C and creatinine in children: effect of including body cell mass. Am J Kidney Dis 59:5057

6. Gao A, Cachat F, Faouzi M, Bardy D, Mosig D, Meyrat BJ, Girardin E, Chehade H (2013) Comparison of the glomerular filtration rate in children by the new revised Schwartz formula and a new generalized formula. Kidney Int 83:524-530

7. Grubb A, Horio M, Hansson LO, Björk J, Nyman U, Flodin M, Larssson A, Bökenkamp A, Yasuda Y, Blufpand H, Lindström V, Zegers I, Althaus H, Blirup-Jensen S, Itoh Y, Sjöström P, Nordin G, Christensson A, Klima H, Sunde K, Hjort-Christensen P, Armbruster D, Ferrero C (2014) Generation of a new cystatin C- based estimating equation for glomerular filtration rate by use of 7 assays standardized to the international calibrator. Clin Chem 60: 974-986

8. Chehade H, Cachat F, Jannot AS, Meyrat BJ, Mosig D, Bardy D, Parvex P, Girardin E (2014) New combined serum creatinine and cystatin C quadratic formula for GFR assessment in children. Clin J Am Soc Nephrol 9:54-63

9. Berg UB, Nyman U, Bäck R, Hansson M, Monemi KA, Herthelius M, Björk J (2015) New standardized cystatin C and creatinine GFR equations in children validated with inulin clearance. Pediatr Nephrol 30:1317-1326

10. de Souza V, Cochat P, Rabilloud M, Selistre L, Wagner M, Hadj-Aissa A, Dolomanova O, Ranchin B, Iwaz J, Dubourg L (2015) Accuracy of different equations in estimating GFR in pediatric kidney transplant recipients. Clin J Am Soc Nephrol 10:463-470

11. Deng F, Finer G, Haymond S, Brooks E, Langman CB (2015) Applicability of estimating glomerular filtration rate equations in pediatric patients: comparison with a measured glomerular filtration rate by iohexol clearance. Transl Res 165:437-445

12. Pottel H, Hoste L, Dubourg L, Ebert N, Schaeffner E, Eriksen BO, Melsom T, Lamb EJ, Rule AD, Turner ST, Glassock RJ, De Souza V, Selistre L, Mariat C, Martens F, Delanaye P (2016) An estimated glomerular filtration rate equation for the full age spectrum. Nephrol Dial Transplant 31:798-806

13. Pottel H, Delanaye P, Schaeffner E, Dubourg L, Eriksen BO, Melsom T, Lamb EJ, Rule AD, Turner ST, Glassock RJ, De Souza V, Selistre L, Goffin K, Pauwels S, Mariat C, Flamant M, Ebert N (2017) Estimating glomerular filtration rate for the full age spectrum from serum creatinine and cystatin C. Nephrol Dial Transplant 32:497-507

14. Blufpand HN, Tromp J, Abbink FC, Stoffel-Wagner B, Bouman AA, Schouten-van Meeteren AY, van Wijk JA, Kaspers GJ, Bökenkamp A (2011) Cystatin C more accurately detects mildly impaired renal function than creatinine in children receiving treatment for malignancy. Pediatr Blood Cancer 57:262-267

15. Blufpand HN, Westland R, van Wijk JA, Roelandse-Koop EA, Kaspers GJ, Bökenkamp A (2013) Heightindependent estimation of glomerular filtration rate in children: an alternative to the Schwartz equation. J Pediatr 163:1722-1727

16. Westland R, Abraham Y, Bokenkamp A, Stoffel-Wagner B, Schreuder MF, van Wijk JA (2013) Precision of estimating equations for GFR in children with a solitary functioning kidney: the KIMONO study. Clin J Am Soc Nephrol 8:764-772

17. den Bakker E, Gemke R, van Wijk JAE, Hubeek I, Stoffel- Wagner B, Grubb A, Bökenkamp A (2017) Accurate 
eGFR reporting for children without anthropometric data. Clin Chim Acta 474:38-43

18. Mueller L, Pruemper C (2016) Performance in measurement of serum cystatin C by laboratories participating in the College of American Pathologists 2014 CYS Survey. Arch Pathol Lab Med 140:207-208

19. Hoste L, Dubourg L, Selistre L, De Souza VC, Ranchin B, Hadj- Aissa A, Cochat P, Martens F, Pottel H (2014) A new equation to estimate the glomerular filtration rate in children, adolescents and young adults. Nephrol Dial Transplant 29:1082-1091

20. Björk J, Grubb A, Sterner G, Nyman U (2011) Revised equations for estimating glomerular filtration rate based on the Lund-Malmö Study cohort. Scand J Clin Lab Invest 71:232-239

21. Leion F, Hegbrant J, den Bakker E, Jonsson M, Abrahamson M, Nyman U, Björk J, Lindström V, Larsson A, Bökenkamp A, Grubb A (2017) Estimating glomerular filtration rate (GFR) in children. The average between a cystatin C- and a creatinine-based equation improves estimation of GFR in both children and adults and enables diagnosing Shrunken Pore Syndrome. Scand J Clin Lab Invest 77: 338-344

22. Inker LA, Schmid CH, Tighiouart H, Eckfeldt JH, Feldman HI, Greene T, Kusek JW, Manzi J, Van Lente F, Zhang YL, Coresh J, Levey AS (2012) Estimating glomerular filtration rate from serum creatinine and cystatin C. N Engl J Med 367:20-29

23. K/DOQI clinical practice guidelines for chronic kidney disease (2002) Evaluation, classification, and stratification. Part 5. Evaluation of laboratory measurements for clinical assessment of kidney disease. Guideline 4. Estimation of GFR. Am J Kidney Dis 39:S76-S92

24. Pottel H, Hoste L, Delanaye P (2015) Abnormal glomerular filtration rate in children, adolescents and young adults starts below $75 \mathrm{~mL} / \mathrm{min} / 1.73 \mathrm{~m}(2)$. Pediatr Nephrol 30:821-828

25. Barlow SE (2007) Expert committee recommendations regarding the prevention, assessment, and treatment of child and adolescent overweight and obesity: summary report. Pediatrics 120(Suppl 4): S164-S192

26. Fredriks AM, van Buuren S, Wit JM, Verloove-Vanhorick SP (2000) Body index measurements in 1996-7 compared with 1980. Arch Dis Child 82:107-112

27. Eckfeldt JH, Karger AB, Miller WG, Rynders GP, Inker LA (2015) Performance in measurement of serum cystatin $\mathrm{C}$ by laboratories participating in the College of American pathologists 2014 CYS survey. Arch Pathol Lab Med 139: 888-893

28. Bargnoux AS, Pieroni L, Cristol JP, Kuster N, Delanaye P, Carlier MC, Fellahi S, Boutten A, Lombard C, GonzalezAntuna A, Delatour V, Cavalier E (2017) Multicenter evaluation of cystatin C measurement after assay standardization. Clin Chem 63:833-841

29. Nordin G (2017) Cystatin C-incremental improvement in measurement and understanding of results. Clin Chem 63:802-803

30. Groesbeck D, Kottgen A, Parekh R, Selvin E, Schwartz GJ, Coresh J, Furth S (2008) Age, gender, and race effects on cystatin C levels in US adolescents. Clin J Am Soc Nephrol 3:1777-1785

31. Yata N, Uemura O, Honda M, Matsuyama T, Ishikura K, Hataya H, Nagai T, Ikezumi Y, Fujita N, Ito S, Iijima K, Saito M, Keneko T, Kitagawa T (2013) Reference ranges for serum cystatin C measurements in Japanese children by using 4 automated assays. Clin Exp Nephrol 17:872-876

32. Schwartz GJ, Brion LP, Spitzer A (1987) The use of plasma creatinine concentration for estimating glomerular filtration rate in infants, children, and adolescents. Pediatr Clin North Am 34: 571-590

33. Björk J, Jones I, Nyman U, Sjöström P (2012) Validation of the Lund-Malmo, Chronic Kidney Disease Epidemiology (CKD-EPI) and Modification of Diet in Renal Disease (MDRD) equations to estimate glomerular filtration rate in a large Swedish clinical population. Scand J Urol Nephrol 46:212-222

34. Evans M, van Stralen KJ, Schon S, Prutz KG, Stendahl M, Rippe B, Jager KJ (2013) Glomerular filtration rateestimating equations for patients with advanced chronic kidney disease. Nephrol Dial Transplant 28:2518-2526

35. Björk J, Grubb A, Gudnason V, Indridason OS, Levey AS, Palsson R, Nyman U (2017) Comparison of glomerular filtration rate estimating equations derived from creatinine and cystatin C: validation in the Age, Gene/Environment Susceptibility- Reykjavik elderly cohort. Nephrol Dial Transplant 33:13891388

36. Ebert N, Loesment A, Martus P, Jakob O, Gaedeke J, Kuhlmann M, Bartel J, Schuchardt M, Tolle M, Huang T, van der Giet M, Schaeffner E (2015) Iohexol plasma clearance measurement in older adults with chronic kidney 
disease-sampling time matters. Nephrol Dial Transplant 30:1307-1314

37. Nyman U, Grubb A, Larsson A, Hansson LO, Flodin M, Nordin G, Lindström V, Björk J (2014) The revised LundMalmo GFR estimating equation outperforms MDRD and CKD-EPI across GFR, age and BMI intervals in a large Swedish population. Clin Chem Lab Med 52:815-824

38. Björk J, Bäck SE, Ebert N, Evans M, Grubb A, Hansson M, Jones I, Lamb EJ, Martus P, Schaffner E, Sjöström P, Nyman U (2018) GFR estimation based on standardized creatinine and cystatin C: a European multicenter analysis in older adults. Clin Chem Lab Med 56:422-435

39. Selistre L, De Souza V, Cochat P, Antonello IC, Hadj-Aissa A, Ranchin B, Dolomanova O, Varennes A, Beyerle F, Bacchetta J, Dubourg L (2012) GFR estimation in adolescents and young adults. J Am Soc Nephrol 23:989-996

40. Ng DK, Schwartz GJ, Schneider MF, Furth SL, Warady BA (2018) Combination of pediatric and adult formulas yield valid glomerular filtration rate estimates in young adults with a history of pediatric chronic kidney disease. Kidney Int 94:170-177

41. den Bakker E, Gemke R, Bökenkamp A (2018) Endogenous markers for kidney function in children: a review. Critical reviews in clinical laboratory sciences 55:163-183

42. Nyman U, Björk J, Lindström V, Grubb A (2008) The Lund-Malmo creatinine-based glomerular filtration rate prediction equation for adults also performs well in children. Scand J Clin Lab Invest 68: 568-576

43. Björk J, Grubb A, Larsson A, Hansson LO, Flodin M, Sterner G, Lindström V, Nyman U (2015) Accuracy of GFR estimating equations combining standardized cystatin $\mathrm{C}$ and creatinine assays: a cross-sectional study in Sweden. Clin Chem Lab Med 53:403-414

44. den Bakker E, Gemke R, van Wijk JAE, Hubeek I, Stoffel-Wagner B, Bökenkamp A (2018) Combining GFR estimates from cystatin $C$ and creatinine-what is the optimal mix? Pediatr Nephrol 33: 1553-1563

45. Grubb A (2010) Non-invasive estimation of glomerular filtration rate (GFR). The Lund model: simultaneous use of cystatin C- and creatinine-based GFR-prediction equations, clinical data and an internal quality check. Scand J Clin Lab Invest 70: 65-70

46. van Roij KG, van der Horst HJ, Hubeek I, van Wijk JA, Bökenkamp A (2017) Discrepant results of serum creatinine and cystatin $C$ in a urological patient. Clin Chem 63:812-814 